\title{
Bulimia nervosa: 25 years on
}

\author{
ROBERT PALMER
}

Twenty-five years ago Gerald Russell published his paper describing and naming bulimia nervosa (Russell, 1979). It was not long afterwards that the disorder was recognised as a common problem affecting perhaps one in a hundred young women in Western societies (Fairburn \& Beglin, 1990). From obscurity, bulimia nervosa rose to prominence. Now almost everyone knows the term; it is part of everyday discourse. Such a rise is not unique - posttraumatic stress disorder is perhaps another example - but it is unusual. Russell's paper described the new disorder as 'an ominous variant of anorexia nervosa'. His achievement was to pick out this syndrome from the many cases of anorexia nervosa that he was seeing in a specialist tertiary service (Russell, 2004). At the same time others were observing not dissimilar states in other settings (Vandereycken, 1994), but it was Russell who produced both the syndrome definition and the name that would last. Russell himself has remarked that a new disorder 'needs to observed and described accurately before becoming accessible to epidemiologists' - that is, before it can be recognised as an entity and become amenable to study (Russell, 2004). It was his rich clinical description that allowed others to see and detect the disorder. Clinicians and researchers alike recognised the usefulness of the concept. An explosion of attention and literature followed over the next decade or so (Theander, 2002); bulimia nervosa had arrived.

\section{DIAGNOSTIC CRITERIA}

Over the past quarter of a century, the concept of bulimia nervosa has wobbled somewhat in its details. However, there has been a clear trend for the diagnostic criteria to settle towards those outlined by Russell in his first paper. The earliest definition, within the American canon, was the DSM-III diagnosis of a disorder called simply 'bulimia', which proved problematically broad as it required the presence of binge eating and little else (American Psychiatric Association, 1980). In DSM-III-R (American Psychiatric Association, 1987), this was replaced by 'bulimia nervosa', with a set of criteria much nearer to those proposed by Russell. These criteria have been refined further with the inclusion of subtypes in DSM-IV (American Psychiatric Association, 1994), but they have not changed in their essentials. The World Health Organization's International Classification has included bulimia nervosa since the publication of ICD-10 in 1992 (World Health Organization, 1992) and its criteria also resemble those of Russell. However, the ICD-10 classification has one quirk, in that bulimia nervosa is made to take precedence over the diagnosis of anorexia nervosa, giving credence to bulimia nervosa as an 'ominous variant'. Thus, people who fulfil the ICD criteria for bulimia nervosa are accorded that diagnosis even when their body weight is very low. In DSM-IV such cases would fall into the category of anorexia nervosa, binge/purging subtype, a designation resulting from a different trumping rule and one that probably accords better with the intuitions of most clinicians, and which has the same level of reliability as major depression (Wade et al, 2000). Despite these variations, it is clear that bulimia nervosa has come to be fully and firmly established in both the major classificatory systems.

\section{TREATMENT}

The identification of bulimia nervosa proved to be a remarkable stimulus to treatment research, with notably positive results. One promising early treatment arose from the psychodynamic tradition but was not further developed or promoted (Lacey, 1983). It was left to those working within the framework of cognitive- behavioural therapy - one is tempted to say 'as always' - to rise adequately to the challenge of the new disorder and develop and evaluate specific treatments (Fairburn et al, 1993b). They did so with gusto. There is now robust evidence that a particular form of this therapy, known as cognitivebehavioural therapy for bulimia nervosa (CBT-BN), is importantly helpful in the disorder, and is capable of leading to full remission of symptoms in approaching half of cases and some improvement in rather more (Fairburn et al, 1993a; Agras et al, 2000). The Oxford group led by Christopher Fairburn has occupied a central position in this respect and they are still refining their treatments (Fairburn et al, 2003). The other psychological treatment for bulimia nervosa with a clear evidence base is interpersonal psychotherapy (IPT), which was included in the trials as a comparison treatment and proved to be efficacious, if somewhat slower in effect than cognitive-behavioural therapy (Fairburn, 1997). The recently published National Institute for Clinical Evidence guideline on the treatment of eating disorders was able to draw upon dozens of trials of psychological and drug treatments for the disorder and to make a clear recommendation in favour of CBT-BN (National Collaborating Centre for Mental Health, 2004). This body of sound treatment research contrasts with the lamentable dearth of adequate evidence about what helps in the 'senior' eating disorder - anorexia nervosa. Russell's paper with its menacing subtitle might have introduced bulimia nervosa as something of an ugly sister, but it is now anorexia nervosa that takes the role of Cinderella.

So, much has happened in the quarter of a century since Russell's paper first described bulimia nervosa. But was it truly a new disorder in the first place? This is a good question, and the answer to most good questions is 'yes and no'. The 'no' reflects the view that there were almost certainly some cases of what would now be termed 'bulimia nervosa' before the 1970s (Vandereycken, 1994; Russell, 2004). The 'yes' reflects what seems to be the fact that what evidence there is suggests that such cases were rare, and that a major increase occurred in the years just before Russell's paper (Russell, 2004). So what led to this increase? That is an even better question, but it is not amenable to a simple or certain answer. However, the apparent rapidity of the rise suggests strongly that psychosocial factors were importantly 
involved. To my knowledge no one has proposed an infectious or toxic origin for the disorder, and the gene pool cannot change that quickly. Of course, that does not mean that genetic factors are not involved, as changes in the environment may expose a previously hidden genetic vulnerability. Genetic susceptibility to bulimia nervosa suggests that much of it may be shared with anorexia nervosa, the incidence of which has remained much the same (Strober \& Bulik, 2002). The relevance of social factors is further supported by the variable distribution of the disorder between societies and subgroups. Bulimia nervosa seems to be a predominantly urban and Western disorder. However, it is being increasingly recognised in the more affluent, urban and Westernised sections of populations throughout the world (Nasser, 1997). What new mix of psychosocial forces might have promoted the new disorder remains a matter of speculation (Palmer, 1998). Russell himself has largely refrained from such speculation, but has emphasised that change in the manifestation of a disease over time is to be expected (Russell, 2004). Such a concept of pathoplasticity implies that there is some more basic - 'underlying' is the usual adjective state that is undergoing the change. What can we say about this basic nosological entity? Is it reasonable to think that it could be discovered and described? The answer depends upon whether the disease in this instance is to be viewed as a real type in the real world, amenable to such discovery, or as a useful conceptual tool to be thought up, defined and developed. There is a dialectic here between two ways of viewing disorders. Practical clinicians may enjoy occasionally pondering such issues, but tend to favour any synthesis that helps them in their work whatever its deeper provenance. In that respect, bulimia nervosa as an idea has clearly proved its worth.

\section{CONCEPTUAL DEVELOPMENT}

The concept of bulimia nervosa as defined by Gerald Russell has stood the test of a quarter of a century of use and scrutiny. It seems likely it will continue to prove useful for the foreseeable future. However, there are issues and problems that remain and that are indeed highlighted by the diagnosis. Thus, there is increasing recognition that the two main eating disorders, as

ROBERT PALMER, FRCPsych, University of Leicester, Department of Health Sciences, Brandon Mental Health Unit, Leicester General Hospital, Gwendolen Road, Leicester LE5 4PW, UK

currently defined, fail to cover many cases of clinically significant eating disorder. Indeed, the biggest single category in many well-diagnosed case series is usually, in DSM-IV terms, the residual diagnosis of 'eating disorders not otherwise specified' (Fairburn \& Harrison, 2003; Turner \& Bryant-Waugh, 2004). For this reason the classification of the eating disorders cannot be considered to be definitive, or even satisfactory. Furthermore, there has been debate about the extent to which the present diagnostic categories do-or should - inform treatment. The so-called transdiagnostic approach to eating disorders emphasises what people with eating disorders have in common rather than what divides them (Fairburn et al, 2003). However, the consideration of such issues in no way undermines the importance of the contribution of those who observe and define patterns of disorder. Indeed, these debates and issues would not be possible without the conceptual tools that they provide. In psychiatry, even in the age of multivariate analysis and molecular medicine, there is an undiminished role for clinical observation and the detailed study of phenomena and mental states. We need to celebrate and to cherish the contribution of thoughtful and creative clinicians, among whom Gerald Russell is an admirable exemplar.

\section{REFERENCES}

Agras, W. S., Walsh, B.T., Fairburn, C. G., et al (2000) A multi-centre comparison of cognitive-behavioural therapy and interpersonal psychotherapy for bulimia nervosa. Archives of General Psychiatry, 57, 459-466.

American Psychiatric Association (1980) Diagnostic and Statistical Manual of Mental Disorders (3rd edn) (DSM-III). Washington, DC: APA.

American Psychiatric Association (1987) Diagnostic and Statistical Manual of Mental Disorders (3rd edn, revised) (DSM-III-R). Washington, DC: APA.

American Psychiatric Association (1994) Diagnostic and Statistical Manual of Mental Disorders (4th edn) (DSM-IV). Washington, DC: APA.

Fairburn, C. G. (1997) Interpersonal psychotherapy for bulimia nervosa. In Handbook of Treatment for Eating Disorders (2nd edn) (eds D. M. Garner \& P. E. Garfinkel), pp. 278-294. New York: Guilford.

Fairburn, C. G. \& Beglin, S. J. (1990) Studies of the epidemiology of bulimia nervosa. American journal of Psychiatry, 147, 40I-408.
Fairburn, C. G. \& Harrison, P. J. (2003) Eating disorders. Lancet, 36I, 407-4I6.

Fairburn, C. G., Jones, R., Peveler, R. C., et al (1993a) Psychotherapy and bulimia nervosa: the longer-term effects of interpersonal psychotherapy, behavior therapy and cognitive behavior therapy. Archives of General Psychiatry, 50, 419-428.

Fairburn, C. G., Marcus, M. D. \& Wilson, G.T. (1993b) Cognitive-behavioral therapy for binge eating and bulimia nervosa: a comprehensive treatment manual. In Binge Eating: Nature, Assessment and Treatment (eds C. Fairburn \& G. T.Wilson), pp. 36I-404. New York: Guilford.

Fairburn, C. G., Cooper, Z. \& Shafran, R. (2003) Cognitive behaviour therapy for eating disorders: a 'transdiagnostic' theory and treatment. Behaviour Research and Therapy, 4I, 509-528.

Lacey, J. H. (1983) Bulimia nervosa, binge eating and psychogenic vomiting: a controlled treatment study and long term outcome. BMJ, 286, 1609-1613.

Nasser, M. (1997) Culture and Weight Consciousness. London: Routledge.

National Collaborating Centre for Mental Health (2004) Eating Disorders: Core Interventions in the Treatment and Management of Anorexia Nervosa, Bulimia Nervosa and Related Eating Disorders. London: British Psychological Society.

Palmer, R. L. (1998) Culture, constitution, motivation and the mysterious rise of bulimia nervosa. European Eating Disorders Review, 6, 8I-83.

Russell, G. F. M. (1979) Bulimia nervosa: an ominous variant of anorexia nervosa. Psychological Medicine, $\mathbf{9}$, $429-448$.

Russell, G. F. M. (2004) Thoughts on the 25th anniversary of bulimia nervosa. European Eating Disorders Review, 12, 139-152.

Strober, M. \& Bulik, C. M. (2002) Genetic epidemiology of eating disorders. In Eating Disorders and Obesity: A Comprehensive Handbook (eds C. G. Fairburn \& K. D. Brownell). New York: Guilford.

Theander, S. (2002) Literature on eating disorders during 40 years: increasing numbers of papers, emergence of bulimia nervosa. European Eating Disorders Review, 10, 386-398.

Turner, H. \& Bryant-Waugh, R. (2004) Eating disorder not otherwise specified (EDNOS): profiles of clients presenting at a community eating disorders service. European Eating Disorders Review, 12, 18-26.

Vandereycken, W. (1994) Emergence of bulimia nervosa as a separate diagnostic entity: review of the literature from 1960 to 1979. International Journal of Eating Disorders, 16, 105-116.

Wade, T. D., Bulik, C. M. \& Kendler, K. S. (2000)

Reliability of lifetime history of bulimia nervosa: comparison with major depression. British Journal of Psychiatry, 177, 72-76.

World Health Organization (1992) The ICD-IO Classification of Mental and Behavioural Disorders: Clinical Descriptions and Diagnostic Guidelines. Geneva: WHO. 